\title{
Framework Proposal for Open Innovation Implementation in SMEs of Regional Innovation Systems
}

\author{
Lindomar Subtil de Oliveira ${ }^{1^{*}}$, Márcia Elisa Soares Echeveste ${ }^{2}$, Marcelo Nogueira Cortimiglia ${ }^{2}$
}

\begin{abstract}
In the literature of Open Innovation (OI), some specific themes, such as elaboration of methods, strategies and systematized processes of implementation are still little discussed. In attempted to fill this research gap, this study aims to present a proposal for a framework for the implementation of OI in Small and Medium-sized Enterprises of Regional Innovation Systems (RIS). As such, it can support the theoretical development related to OI implementation methods and tools. The constructivist method was used in the development of the framework, which represents the Implementation Process of OI (IPOI), consisting of 5 stages: (i) diagnosis of RIS; (ii) diagnosis of the enterprise; (iii) preparation; (iv) implementation; and (v) monitoring and control. The unfolding of this process in stages and measurement systems allows us to understand the elements and Critical Success Factors (CSF) that interfere in the improvement of the capacity of innovation in SMEs inserted in RIS.
\end{abstract}

Keywords: Open Innovation process; Critical Success Factors; Small and Medium-sized Enterprises; Regional Innovation System.

Submitted: January $12^{\text {th }}, 2019 /$ Approved: June $14^{\text {th }}, 2019$

\section{Introduction}

Although recent research has addressed the development of methods and tools to understand and support OI practices in enterprises (Çubukcu and Gümüs 2015), few report formal, documented and structured strategies for implementing OI in SMEs (Grönlund, Sjödin, and Frishammar 2010; Krause and Schutte 2015). Likewise, there is a shortage of studies that deeply evaluate the CSFs and how these factors can be incorporated into the stages of a process that facilitates and guides the implementation of OI in SMEs of RIS.

RIS are potential environments that can favor the implementation of OI in SMEs, by cooperation, partnerships, technological transfers, sharing of knowledge between public and private institutions, approaching of private investors, and legal stimulus for innovation (Cooke 2005; Garcia and Chavez 2014; Oliveira et al. 2017).

Given this context, the main objective of this article is to present a proposal of a representative framework of the Implementation Process of OI (IPOI) in SMEs of RIS. Following the steps of the constructivist method, the proposed framework was delineated in 5 stages: (i) diagnosis of RIS; (ii) diagnosis of the enterprise; (iii) preparation; (iv) implementation; and (v) monitoring and control.

\section{Method}

In this study, the seven main steps of the Design Science Research (DSR) method were adopted (Fig.1), which of used in several studies of the literature (Kasanen, Lukka, and Siitonen 1993; Geerts 2011).
Figure 1: Stages of the DSR method

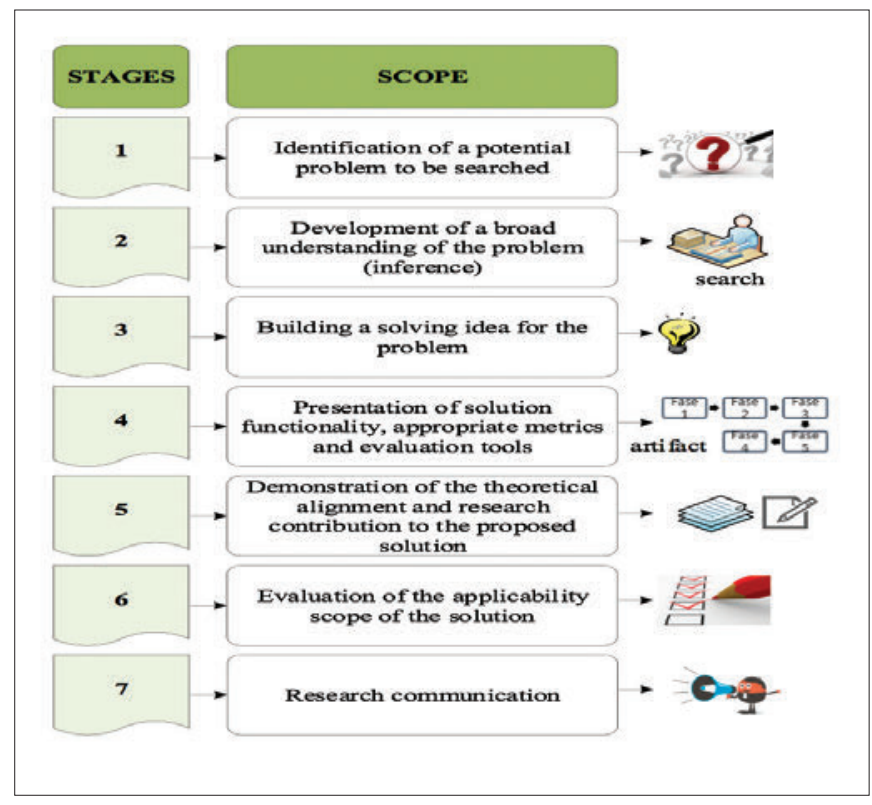

In the sequence, the unfolding of each steps is described.

\section{Identification of the problem (1)}

Currently, there are few studies in the literature that address the proposition of methods, models, systems, technological platforms and structures that offer support and orientation to the implementation of OI (Lee et al. 2010; Wallin and Von Krogh 2010; Grönlund, Sjödin, and Frishammar 2010; Gulshan 2011; Herskovits, Grijalbo, and Tafur 2013; Yoon and Song 2014; Çubukcu and Gümüs 2015).

1) Department of Business Administration, Universidade Tecnológica Federal do Paraná, UTFPR, Francisco Beltrão, PR - Brazil.

2) Department of Industrial Engineering, Universidade Federal do Rio Grande do Sul, UFRGS, Porto Alegre, RS - Brazil.

*Corresponding author: lindomar@utfpr.edu.br 
Note that most of the studies and cases presented in the literature emphasize the use of OI mainly among multinationals and large high-tech companies (Wynarczyk, Piperopoulos, and Mcadam 2013). Thus, given the need to explore new fields of OI application, specially in SMEs (Van De Vrande et al. 2009), and to propose models and processes that enable the implementation of this strategy, the following research problem was raised: How should a process be structured to guide the implementation of OI in SMEs of RIS?

\section{Understanding the problem (2)}

The literature review was based on the implementation approach of tools, processes, information and knowledge systems, individual factors, and team formation for implementation (Cormican and Sullivan
2004); process model to assist managers in the implementation of OI projects (Wallin and Von Krogh 2010); assessment of organizational capacities in the product development process and technological evaluation model (Gusberti, Werner, and Echeveste 2011); method and model of knowledge transfer (Frank and Echeveste 2012); OI program and its impacts on value creation of the enterprise (Herskovits, Grijalbo, and Tafur 2013); method of portfolio management of innovation projects (Bagno et al. 2016); model of innovation management systems in SMEs (Bagno et al. 2016); among others.

In addition, the research was based on the main CSF of OI literature (Table 1) presented in the work of Oliveira et al. (2016).

Table 1. Main categories and CSF

\begin{tabular}{|c|c|}
\hline Category & CSF/Description \\
\hline 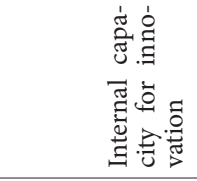 & $\begin{array}{l}\text { 3. Technical skills: Promote and develop technical skills related to innovation (e.g. technological, marketing, financial, commercial and } \\
\text { business management); } \\
\text { 4. External knowledge input: Promote information and an open knowledge flow, also connected with the external environment; }\end{array}$ \\
\hline 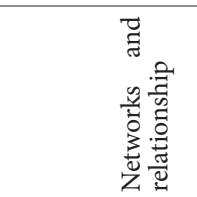 & $\begin{array}{l}\text { 5. Relationship management: Promote efficient coordination mechanisms for external partnerships, as well as for the selection and } \\
\text { prioritization of potential partners; } \\
\text { 6. Trust relationships: Promote confidentiality agreements with partners to minimize risks and ensure correct appropriation of results } \\
\text { and revenue sharing; }\end{array}$ \\
\hline
\end{tabular}

7. Innovation strategy: Clearly define the strategic positioning of innovation in the enterprise (e.g. objectives in terms of product or
process innovation, radical or incremental);
8. Strategic resources: Provide the financial, technological and human resources necessary to implement the OI;

Also, publications that aligned with the objectives of the study and that dealt with OI models, methods, tools and processes were analyzed in the research.

\section{Idea to solve the problem (3)}

The proposed framework integrates aspects of management, predetermined procedures, stages and documentation standardization, establishment of stages and external relationships, and metrics that allow the assessment of the process performance (Steninger 2014; Bagno et al. 2016). The process also adds key elements and CSF, sequentially demonstrating the most appropriate decision paths and alternatives for implementation, and the required resources. The objective is to prescribe the various activities and actions that must be performed and controlled by managers to better adapt and succeed in conducting an OI project (Boscherini et al. 2010).

\section{Functionality of solution and evaluation tools (4)}

The IPOI framework (Fig.2) consists of 5 stages: (i) Diagnosis of RIS; (ii) Diagnosis of the enterprise; (iii) Preparation; (iv) Implementation; and (v) Monitoring and control. In each of these stages, tools that can be executed as guides for implementation and evaluation of IPOI are suggested. 
Figure 2: IPOI Framework

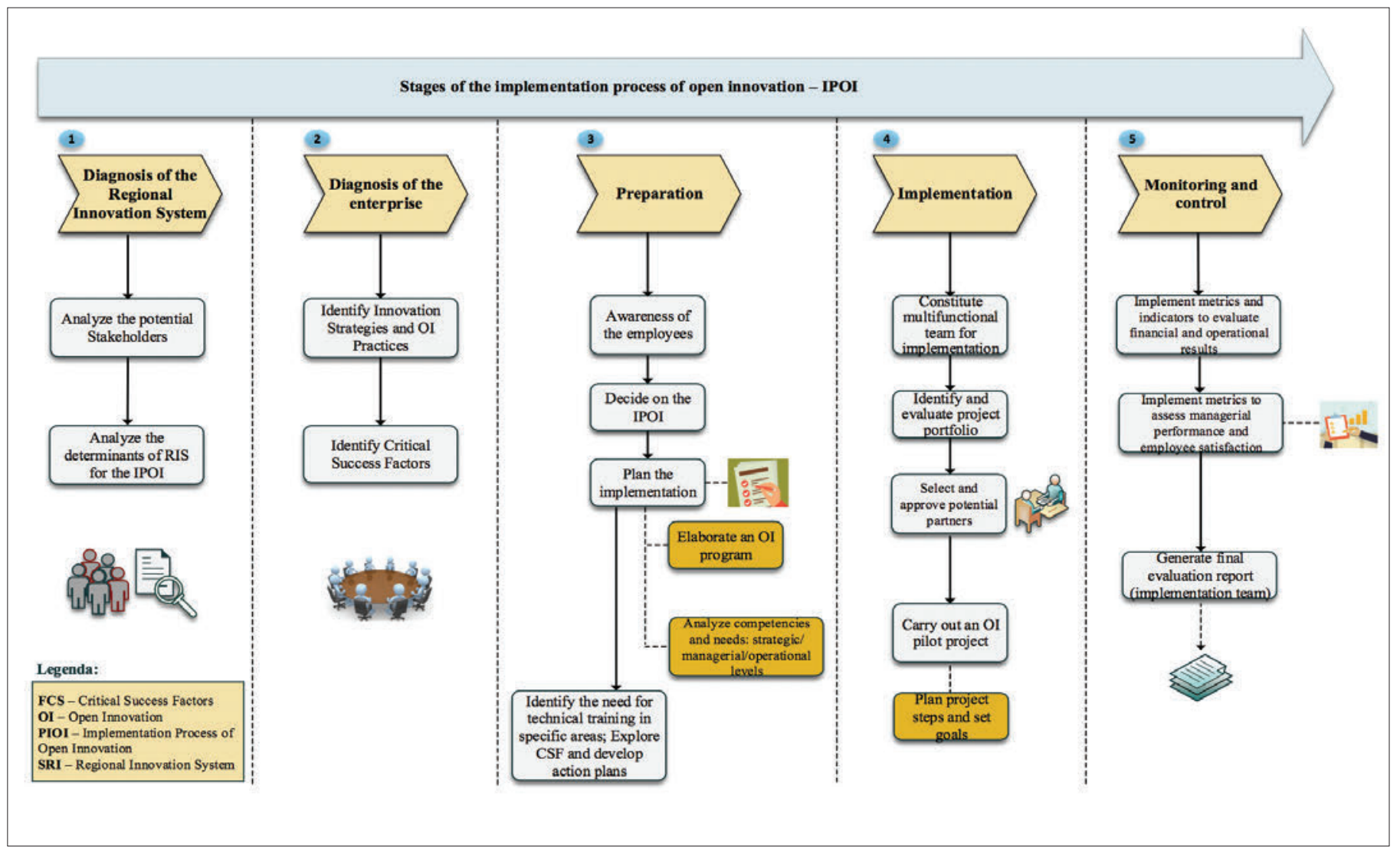

\section{Stages of IPOI}

\section{Diagnosis of RIS}

This stage is a diagnostic of the RIS macro environment to analyze the potential stakeholders and determinants of the system for IPOI (Oliveira et al. 2017). By a Swot matrix, the stakeholders' knowledge about RIS and the potential for OI implementation are better evaluated. Basically, four important aspects must be analyzed: political/ governmental, economic, availability of labor, and managerial.

\section{Diagnosis of the enterprise}

At this stage, the strategic committee must carry out a diagnosis of innovation and OI practices implemented by the enterprise and identify the CSF for OI implementation. Based on the CSF of Table 1, the enterprise is advised to assess which are most impacting to its context and to draw up specific action plans, eliminating or mitigating the impact caused by them.

\section{Preparation}

This stage comprehend four main activities: a) awareness of employees; b) implementation decision; c) implementation planning; and d) analysis of the CSF and preparation of the action plan. The strategic committee must define a preliminary action plan to assist managers to make a "self-analysis" of the company's internal and external conditions related to managerial, structural, relationship, strategic, technological and cultural aspects. Awareness aims to demonstrate the potential of OI and the benefits of participating in external collaborative projects. It is suggested to carry out an internal workshop to encourage employees to present their ideas and projects. This awareness-raising activity will help in the decision on the implementation of the OI, which may be for strategic, managerial or market orientation (Lichtenenter 2008; Cheng and Huizingh 2014), necessity or opportunity of business model readjustment (Saebi and Foss 2015).

Implementation planning requires an OI program (Herskovits, Grijalbo, and Tafur 2013). A detailed analysis must be done at the strategic/managerial and operational levels of the main competencies and needs of the enterprise. At the managerial level, technical, scientific, technological and complementary competencies are required, such as sales and marketing (Wynarczyk, Piperopoulos, and Mcadam 2013; Stefanovitz and Nagano 2014), people management policies and practices, leadership style of team coordinators and strategic orientation to innovation (Rosenbusch, Brinckmann, and Bausch 2011).

Finally, at this stage the CSF presented in Table 1 should also be explored, proposing action plans and operational tools for each of them, preferably for the CSF that were considered more impacting for the company context in the diagnostic stage. Table 3 lists a set of actions and tools proposed by the authors of this study and supported by the literature, which can be worked on each dimension to deal with the CSF and the expected results of these actions. 
Table 3. Actions and proposed tools

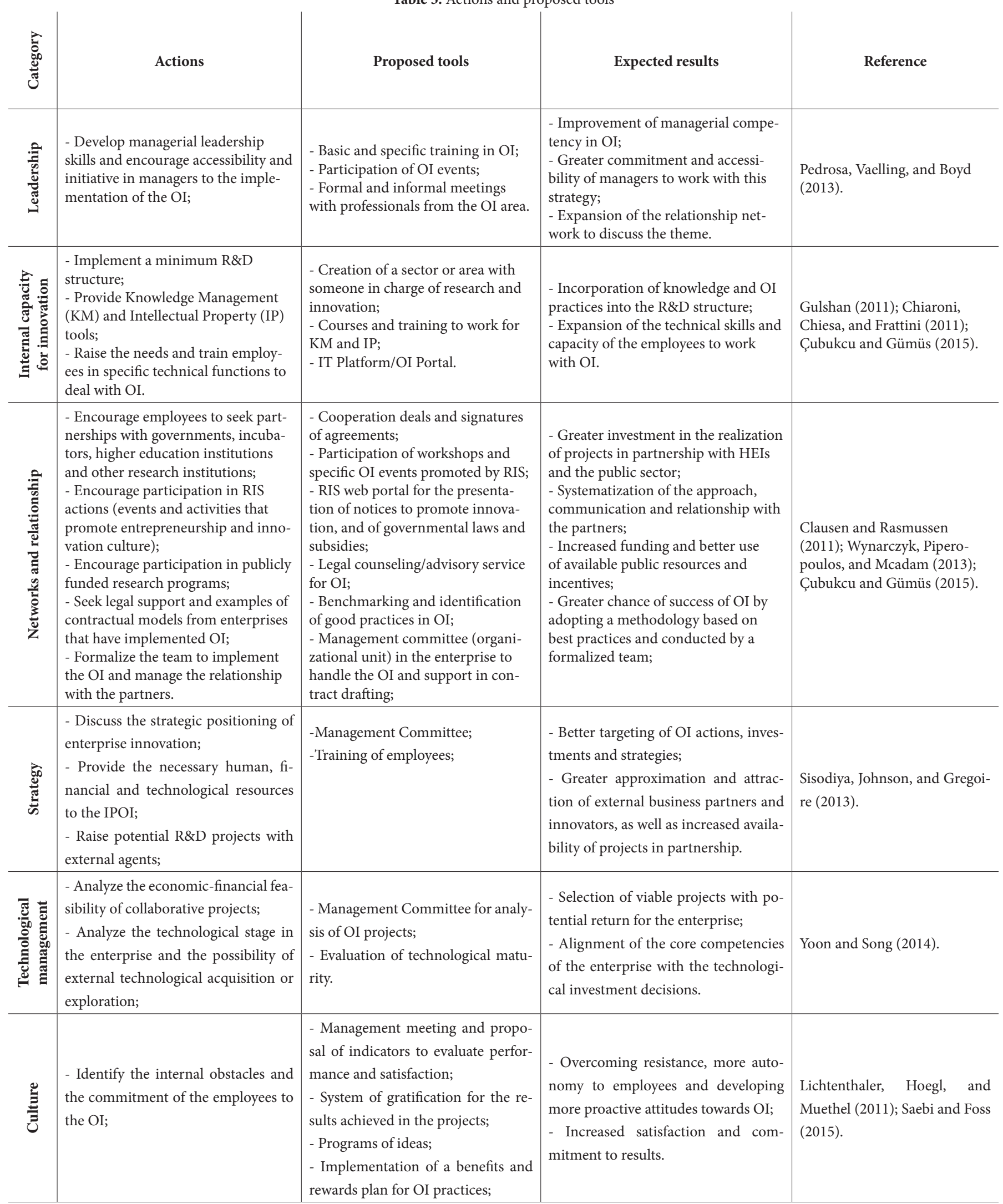




\section{Implementation}

This stage comprises four important parts: a) to set up an implementation team; b) to analyze the portfolio of projects; c) to choose/select the partners; and d) to carry out a pilot project.

The implementation team should be composed of people of the tactical and operational hierarchical levels (Bagno et al. 2016), managers and leaders with knowledge and skills in R\&D areas or with experience in projects of this nature (Wynarczyk 2013). This team will manage the project portfolio (Bagno et al. 2016), identifying and evaluating internal and external projects with the potential to be developed collaboratively (Grönlund, Sjödin, and Frishammar 2010). Internally, the essential projects of the enterprise must be prioritized, which may include process improvement, development of a technology or solution for new products. Collaborative projects should consider the market interests of both parties (Narula 2004) and the core competency of the enterprise; the imminent stage of the project and the opportunity for risk sharing (Lo Nigro, Morreale, and Enea 2014). Externally, projects may involve collaboration with independent developers, cooperation with incubators (Clausen and Rasmussen 2011), or technological transfer and acquisition projects in universities.

Another important activity of this stage is to select and approve external partners (Narula 2004). On one hand, companies know the needs of the market and know where to look for the best partners to develop innovation. On the other hand, HEIs also develop technological innovations, products and patents that raise the interest of enterprises. Therefore, it is recommended to use a tool that systematically define criteria for evaluating and selecting partners (Yoon and Song 2014).

The fourth part of this stage is to execute an OI pilot project (Boscherini et al. 2010). If the chosen project is rejected by the partner, the enterprise may have to search for one with an interest in implementing it or may have to explore another project with potential for implementation in the portfolio. The implementation stage requires joint planning with the partner to discuss project steps, set common goals, outcomes, themes, and objectives, such as:

Cost/benefit: Predict the return on investment of the parties through evaluation methods (Return on Investment - ROI, rate of return), point out product or process improvements, and estimate incomes of new products (Chesbrough 2004, Chiaroni, Chiesa, and Frattini 2011).

Time: Establish a schedule to determine the sequence of activities and processes that will be carried out, estimate execution time, define responsibilities and performers, and need of financial resources, people, technology, etc. (Steninger 2014).

Legal/contractual support: Establishing confidentiality contracts (Narula 2004) is a crucial factor to ensure the success of technological projects and interorganizational innovation, since the criteria and rules related to revenues and profit sharing among participants are defined, as well as intellectual property rights and licensing agreements.
Training/technical necessity: The way people deal with innovation interfere in the IPOI (Chesbrough 2006). Thus, partners must identify the necessary technical and operational skills, and develop and provide adequate training. Partners can stimulate the pursuit of knowledge outside the organization through worker mobility (De Jong, Kalvet, and Vanhaverbeke 2010), and OI benchmarking with other stakeholders.

\section{Monitoring and control}

The results of the IPOI should be evaluated by a system of metrics that allows to measure the financial and operational results, the management performance and the satisfaction of the employees and other stakeholders involved in the project (Bagno et al. 2016). The metrics generate indicators that help in decision making and monitoring what was planned, evaluating the evolution of the enterprise in the process of developing innovation in collaboration with external partners.

Finally, the implementation team should prepare a final report of the IPOI reporting the experiences and practical lessons learned, the critical points, the failures and failure factors of the project.

Theoretical alignment and contribution of the research to the solution (5) Three important contributions were generated by this research: First, the methodological representation as a framework that seeks to solve the problem in a more effective and efficient way, bringing together the main elements and CSF of OI implementation. Secondly, through theoretical foundation, we sought to broaden and improve the existing knowledge base on OI, developing a new implementation process for SMEs of RIS. Third, suggesting for each stage of the IPOI tools that aim to assist in the implementation and evaluation of the solution.

\section{Evaluation of the applicability scope of the solution (6)}

This stage consists in submitting the proposed framework for the assessment by experts and academics. This step has not been applied in this article, which will be carried out in future studies.

\section{Research communication (7)}

This stage aims to present the results of the research to the public oriented both technology and management.

\section{Conclusions and suggestions for future studies}

This study presented a proposal for a framework to implement OI in SMEs of RIS. For managers, the framework represents a methodological tool that aims to help the enterprise in the IPOI, orienting about the necessary resources (e.g. technical/managerial skills, people, technology, etc.), actions and decision making in the process. Above all, it offers the managers an understanding of the elements and CSF that interfere in the improvement of innovation capacity in SMEs inserted in an RIS context. For academia, it makes a specific contribution to implementation processes, emphasizing mainly the CSF and other determinants that impact the success of this strategy. The framework is based on a consistent theoretical foundation that helps filling the gap of the literature in the OI process development field and broaden current knowledge about this theme. 
Although IPOI is a generic instrument, it can cause different impacts on the management and organization system of enterprises operating in different segments or may be influenced by other variables that may not have been evaluated in this study. Thus, case studies in different types of SMEs, in order to implement the framework, evaluate and compare the various impacts and results generated by the IPOI, proves to be an opportunity for future research agenda.

\section{References}

Bagno, R.B., et al. 2016. Cartilha empresarial do Projeto FAZ-NAGI/ MG Modelo das Duas Rodas: Referência para sistemas de gestão da inovação em PMEs. Minas Gerais - Brazil: UFMG/UFV.

Boscherini, L., Chiaroni, D., Chiesa, V., \& Frattini, F. 2010. "How to use pilot projects to implement open innovation". International Journal of Innovation Management 14 (6): 1065-1097.

Cheng, C.C.J., \& Huizingh, E.K.R.E. 2014. "When is open innovation beneficial? The role of strategic orientation". Journal of Product Innovation Management 31 (6): 1235-1253.

Chesbrough, H. W. 2004. "Managing open innovation". Research Technology Management 47 (1): 23-26.

Chesbrough, H.W. 2006. "Open Innovation: A New Paradigm for Understanding Industrial Innovation”. In: Chesbrough, H.W., Vanhaverbeke, W., West, J. Open innovation: Researching a new paradigm. J. Oxford: Oxford University Press, 1-12.

Chiaroni, D., Chiesa, V., \& Frattini, F. 2011. “The Open Innovation Journey: How firms dynamically implement the emerging innovation management paradigm". Technovation 31 (1): 34-43.

Clausen, T., \& Rasmussen, E. 2011. "Open innovation policy through intermediaries: the industry incubator programme in Norway”. Technology Analysis \& Strategic Management 23 (1): 75-85.

Cooke, P. 2005. "Regionally asymmetric knowledge capabilities and open innovation: Exploring 'Globalisation 2' - A new model of industry organisation". Research Policy 34 (8): 1128-1149.

Cormican, K., \& Sullivan, D.O. 2004. "Auditing best practice for effective product innovation management". Technovation 24 (10): 819-829.

Çubukcu, A., \& Gümüs, B. 2015. "Systematic Design of an Open Innovation Tool”. Procedia Social and Behavioral Sciences (195): 2859-2867.

De Jong, J.P.J., Kalvet, T., \& Vanhaverbeke, W. 2010. "Exploring a theorethical framework to structure the public policy implications of open innovation”. Technology Analysis \& Strategic Management 22 (8): 877-896.

Frank, A.G., \& Echeveste, M. 2012. "Knowledge transfer between NPD project teams: A method for the identification of improvement opportunities". International Journal of Quality \& Reability Management 29 (3): 242-264.
Garcia, B. C., \& Chavez, D. 2014. "Network-based innovation systems: A capital base for the Monterrey city-region, Mexico". Expert Systems with Applications 41 (12): 5636-5646.

Geerts, G.L. 2011. "A design science research methodology and its application to accounting information systems research". International Journal of Accounting Information Systems 12 (2): 142-151.

Grönlund, J., Sjödin, D.R., \& Frishammar, J. 2010. “Open Innovation and the Stage- Gate Process: A Revised Model for New Product Development”. California Management Review 52 (3): 105-131.

Gulshan, S.S. 2011. "Innovation Management: Reaping the benefits of Open Platforms by assimilating internal and external innovations". Procedia - Social and Behavioral Sciences 25, 46-53.

Gusberti, T.D.H., Werner, L., \& Echeveste, M.E.S. 2011. “Definição de constructos para avaliação das capacidades no processo de desenvolvimento de produto". Congresso Brasileiro de Gestão da Inovação e Desenvolvimento de Produtos - CBGDP, Porto Alegre - RS, Brazil, sept. 1-13.

Herskovits, R., Grijalbo, M., \& Tafur, J. 2013. "Understanding the main drivers of value creation in an open innovation program". International Entrepreneurship and Management Journal 9 (4): 631-640.

Kasanen, E., Lukka K., \& Siitonen A. 1993. "The constructive approach in management accounting". Journal of Management Accounting Research 5, 243-264.

Krause, W., \& Schutte, C.S.L. 2015. "A perspective on open innovation in small- and medium-sized enterprises in South Africa, and design requirements for an open innovation approach". South African Journal of Industrial Engineering 26 (1): 163-178.

Lee, S., Park, G., Yoon, B., \& Park, J. 2010. “Open innovation in SMEsAn intermediated network model”. Research Policy 39 (2): 290-300.

Lichtenthaler, U. 2008. "Open innovation in practice: An analysis of strategic approaches to technology transactions". Ieee Transactions on Engineering Management 55 (1): 148-157.

Lichtenthaler, U., Hoegl, M., \& Muethel, M. 2011. "Is Your Company Ready for Open Innovation?" Mit Sloan Management Review 21 (sept.): 1-6.

Lo Nigro, G., Morreale, A., and Enea, G. 2014. "Open Innovation: A real option to restore value to the biopharmaceutical R\&D”. International Journal of Production Economics 149 (march): 183-193.

Narula, R. 2004. "R\&D collaboration by SMEs: new opportunities and limitations in the face of globalization”. Technovation 24 (2): 153-161.

Oliveira, L.S.O.; Echeveste, M.E.S.; Cortimiglia, M.N.; \& Prá Carvalho, A. 2016. "Análise bibliométrica e principais dimensões da literatura sobre open innovation". International Journal of Knowledge Engineering Management. 5 (11): 116-135. 
Oliveira, L.S.O., Echeveste, M.E.S., Cortimiglia, M.N., \& Gonçalves, C.G.C. 2017. "Analysis of determinants for Open Innovation Implementation in Regional Innovation Systems". Innovation \& Management Review - RAI 14 (2): 119-129.

Pedrosa, A. D. M., Vaelling, M., \& Boyd, B. 2013. "Knowledge related activities in open innovation: managers' characteristics and practices". International Journal of Technology Management 61 (3/4): 254-273.

Rosenbusch, N., Brinckmann, J., \& Bausch, A. 2011. "Is innovation always beneficial?. A meta-analysis of the relationship between innovation and performance in SMEs". Journal of Business Venturing 26 (4): 441-457.

Saebi, T., \& Foss, N. J. 2015. "Business models for open innovation: Matching heterogeneous open innovation strategies with business model dimensions". European Management Journal 33 (3): 201-213.

Sisodiya, S. R., Johnson, J. L., \& Gregoire, Y. 2013. "Inbound open innovation for enhanced performance: Enablers and opportunities". Industrial Marketing Management 42 (5): 836-849.

Stefanovitz, J.P., \& Nagano, M.S. 2014. “Gestão da inovação de produto: proposição de um modelo integrado”. Production 24 (2): 462-476.
Steninger, S. 2014. "Open Innovation and Barriers to Adoption: A case study in the construction Industry". Master's thesis in the Master's Programme, Entrepreneurship and Business Design - Chalmers University of Technology - Gothenburg, Sweden.

Van De Vrande, V., De Jong, J.P.J., Vanhaverbeke, W., \& Rochemont, M. 2009. "Open innovation in SMEs: Trends, motives and management challenges”. Technovation 29 (6-7): 423-437.

Wallin, M. W., \& Von Krogh, G. 2010. “Organizing for open innovation: Focus on the integration of knowledge". Organizational Dynamics 39 (2): 145-154.

Wynarczyk, P. 2013. "Open innovation in SMEs: A dynamic approach to modern entrepreneurship in the twenty-first century". Journal of Small Business and Enterprise Development 20 (2): 258-278.

Wynarczyk, P., Piperopoulos, P., \& MCadam, M. 2013. “Open innovation in small and medium-sized enterprises: An overview". International Small Business Journal 31 (3): 240-255.

Yoon, B., \& Song, B. 2014. "A systematic approach of partner selection for open innovation”. Industrial Management \& Data Systems 114 (7): 1068-1093. 